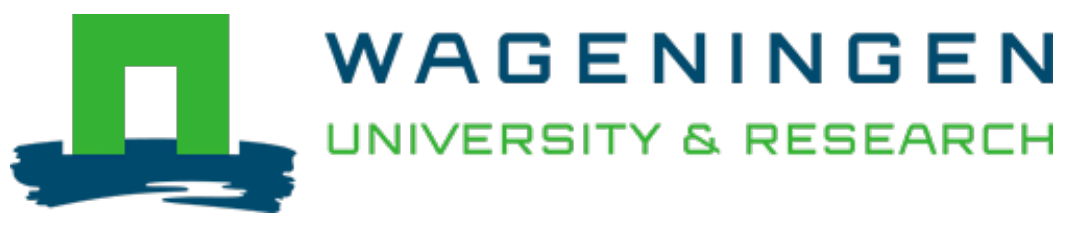

\title{
Suspensor-derived somatic embryogenesis in Arabidopsis
}

Development

\author{
Radoeva, Tatyana; Albrecht, Catherine; Piepers, Marcel; Vries, Sacco; Weijers, Dolf \\ https://doi.org/10.1242/dev.188912
}

This article is made publicly available in the institutional repository of Wageningen University and Research, under the terms of article $25 \mathrm{fa}$ of the Dutch Copyright Act, also known as the Amendment Taverne. This has been done with explicit consent by the author.

Article $25 \mathrm{fa}$ states that the author of a short scientific work funded either wholly or partially by Dutch public funds is entitled to make that work publicly available for no consideration following a reasonable period of time after the work was first published, provided that clear reference is made to the source of the first publication of the work.

This publication is distributed under The Association of Universities in the Netherlands (VSNU) 'Article $25 \mathrm{fa}$

implementation' project. In this project research outputs of researchers employed by Dutch Universities that comply with the legal requirements of Article $25 \mathrm{fa}$ of the Dutch Copyright Act are distributed online and free of cost or other barriers in institutional repositories. Research outputs are distributed six months after their first online publication in the original published version and with proper attribution to the source of the original publication.

You are permitted to download and use the publication for personal purposes. All rights remain with the author(s) and / or copyright owner(s) of this work. Any use of the publication or parts of it other than authorised under article $25 \mathrm{fa}$ of the Dutch Copyright act is prohibited. Wageningen University \& Research and the author(s) of this publication shall not be held responsible or liable for any damages resulting from your (re)use of this publication.

For questions regarding the public availability of this article please contact openscience.library@wur.nl 


\title{
Suspensor-derived somatic embryogenesis in Arabidopsis
}

\author{
Tatyana Radoeva*, Catherine Albrecht ${ }^{\star}$, Marcel Piepers, Sacco de Vries ${ }^{\dagger}$ and Dolf Weijers ${ }^{\dagger}$
}

\begin{abstract}
In many flowering plants, asymmetric division of the zygote generates apical and basal cells with different fates. In Arabidopsis thaliana, the apical cell generates the embryo while the basal cell divides anticlinally, leading to a suspensor of six to nine cells that remain extra-embryonic and eventually senesce. In some genetic backgrounds, or upon ablation of the embryo, suspensor cells can undergo periclinal cell divisions and eventually form a second twin embryo. Likewise, embryogenesis can be induced from somatic cells by various genes, but the relationship with suspensor-derived embryos is unclear. Here, we addressed the nature of the suspensor to embryo fate transformation and its genetic triggers. We expressed most known embryogenesis-inducing genes specifically in suspensor cells. We next analyzed morphology and fate-marker expression in embryos in which suspensor division was activated by different triggers to address the developmental paths towards reprogramming. Our results show that reprogramming of Arabidopsis suspensor cells towards embryonic identity is a specific cellular response that is triggered by defined regulators, follows a conserved developmental trajectory and shares similarity to the process of somatic embryogenesis from postembryonic tissues.
\end{abstract}

KEY WORDS: Arabidopsis, Plant embryogenesis, Reprogramming, Suspensor, Totipotency

\section{INTRODUCTION}

In flowering plants (angiosperms), embryogenesis is initiated by fertilization of the egg cell. In Arabidopsis, this gives rise to the zygote, which undergoes an asymmetric division to form two cells with distinct fates: an apical embryonic cell and a basal extra-embryonic cell from which the suspensor develops. The apical cell then continues to divide in a strictly regular manner to give rise to most tissues and cell types of the seedling (Palovaara et al., 2016). Of the approximately seven suspensor cells, only the uppermost, the hypophysis, contributes to the generation of the root meristem. The common view is that suspensor cells supply the growing embryo with nutrients and growth regulators, fix the developing embryo to the micropylar cavity within the seed and might function as a reservoir of embryogenic cells in case the primary embryo fails (Kawashima and Goldberg, 2010; Radoeva and Weijers, 2014). Despite its quiescence under normal conditions, secondary embryos can be formed from suspensor cells in many plant species under specific conditions (Lakshmanan and Ambegaokar, 1984). Suspensor-derived embryogenesis can be experimentally

Laboratory of Biochemistry, Wageningen University, Stippeneng 4, 6708 WE

Wageningen, The Netherlands.

*These authors contributed equally.

†Authors for correspondence (sacco.devries@wur.nl, dolf.weijers@wur.nl)

(D) T.R., 0000-0002-7742-7817; S.d.V., 0000-0001-9454-775X; D.W., 0000-00034378-141X

Handling Editor: Ykä Helariutta

Received 29 January 2020; Accepted 8 June 2020 induced by stress treatments (Haccius, 1955), by impairment of the primary embryo through radiation (Haccius, 1955), mutations (such as sus and twn; Schwartz et al., 1994; Vernon and Meinke, 1994), by genetic ablation (Weijers et al., 2003), by expression of the auxin response inhibitor protein bodenlos (bdl; Rademacher et al., 2012) or by laser irradiation (Gooh et al., 2015; Liu et al., 2015). Thus, suspensor cells can be regarded as a dormant pool of cells that can switch to embryo identity when necessary. Re-initiation of embryonic cell fate in suspensor cells has the advantage that a precise sequence of reprogramming, the possible occurrence of cell autonomy and lateral inhibition as well as stochastic and epigenetic aspects, can be analyzed in a predictable fashion in only a few cells (Radoeva and Weijers, 2014; De Vries and Weijers, 2017).

The ability of plant cells to be reprogrammed towards embryogenesis has long been recognized and has been the basis for protocols of somatic embryogenesis (Egertsdotter et al., 2019). In the past decades, several factors have been identified that can facilitate or trigger the induction of somatic embryos. Genes such as the leucine-rich repeat receptor-like kinase (LRR-RLK) SOMATIC EMBRYOGENESIS RECEPTOR-LIKE KINASE 1 (SERK1) appear to promote the capability to form somatic embryos (Hecht et al., 2001), whereas transcriptional regulators of the BABY BOOM (BBM) and LEAFY COTYLEDON (LEC) pathway appear to directly induce somatic embryos (Horstman et al., 2017). In addition, genes from the plant-specific RWP-RK domain-containing (RKD) family, involved in maintaining egg cell identity, are able to induce loss of cell identity (Köszegi et al., 2011) or actively promote somatic embryogenesis (Waki et al., 2011) upon ectopic expression. However, these genes were identified and tested in different experimental systems, ranging from Brassica microspores to Arabidopsis meristems and seedlings. This makes it challenging to infer whether these factors are part of the same genetic network or pathway, and it is unclear how these factors, or the process of somatic embryogenesis, relates to the reprogramming of suspensor cells.

Here, we have exploited the simple and predictable suspensor system to address these issues. We have first tested the ability of 12 different genes, representative of the somatic embryo pathways, to induce suspensor-derived twin seedlings. We next compared suspensor-derived embryogenesis induced by three different triggers to define the developmental trajectory underlying reprogramming. We found that a common sequence of events underlies reprogramming. First, suspensor identity is lost, which is closely connected with the activation of cell division. Embryo identity is gained only later, either concomitantly with or following the activation of division. Our work shows that suspensor reprogramming is activated by specific triggers, but also reveals a striking similarity between suspensor-derived and other somatic embryogenesis processes.

\section{RESULTS}

Suspensor embryogenesis requires specific genetic triggers Several genes have previously been reported to trigger embryogenesis when ectopically overexpressed and have therefore been defined as master embryonic or meristematic regulators 
(reviewed by Ikeuchi et al., 2013; Radoeva and Weijers, 2014). Nevertheless, their ability to induce embryogenesis has been tested in diverse model systems (Boutilier et al., 2002; Hecht et al., 2001; Waki et al., 2011; Zuo et al., 2002). It is therefore difficult to compare their activities and to address whether all of these genes indeed trigger embryo identity or some other process contributing to the development of somatic embryos. We decided to use the predictable suspensor-derived embryogenesis as an experimental system to test known embryo inducers for their ability to convert suspensor cells into secondary twin embryos and ultimately into twin seedlings.

We selected 12 genes and tested their ability to promote embryo initiation. These included transcriptional regulators, such as $L E C$, BBM, RKD, WUSCHEL (WUS) and WUSCHEL-RELATED $H O M E O B O X(W O X)$, and the receptor-like kinase SERK1 (Table 1). Each was misexpressed in the developing suspensor using a twocomponent GAL4/UAS system from the M0171-GAL4 driver line (Rademacher et al., 2012; Radoeva et al., 2016). This same approach previously led to excessive suspensor cell divisions when the bdl/iaa12 protein was expressed (Rademacher et al., 2012). However, twin seedlings resulting from ubiquitous $b d l$ overexpression were only seen in RPS5A $>>b d l$ embryos (Rademacher et al., 2012). Although excessively dividing cells in M0171 $>>b d l$ suspensors did at times resemble embryo-like structures, twin seedlings were not observed in these embryos (Radoeva et al., 2019).

After transforming transgenes driving each embryogenesis regulator from the GAL4-dependent $U A S$ promoter into the M0171 GAL4 driver line, we screened primary transformants for twin seedlings, a phenotype that is not found in wild type $(0 \%$; $n>500$ : Fig. 1B). This is the most stringent selection criterium for suspensor-derived embryos, given that it not only requires the initiation and formation of a second embryo but also maturation and survival of desiccation, dormancy and germination. Strikingly, although many of these genes had been shown to promote embryogenesis in various conditions, only a few could induce twin-seedling development at a level that could be detected in this assay (Fig. 1D; Fig. S1; Table 1). Although a very low percentage of twin formation was seen with WUS $(3.3 \% ; n=30)$ and RKD4 $(1.8 \%$; $n=54)$, RKD1 expression led to the frequent recovery of twin seedlings $(29 \% ; n=17)$. Although the WUS- or RKD1-expressing plants were fertile and could be carried to later generations, RKD4 expression resulted in distorted seedlings that did not develop into

Table 1. Genes tested for their ability to produce twin seedlings

\begin{tabular}{lllll}
\hline Gene & Reference & $\begin{array}{l}\text { Lines } \\
(n)\end{array}$ & $\begin{array}{l}\text { Twins } \\
(n / \%)\end{array}$ & $\begin{array}{l}\text { Heritable twins } \\
\text { (number of lines) }\end{array}$ \\
\hline LEC1 & Lotan et al. (1998) & 17 & $0 /<5.9$ & 0 \\
LEC2 & Stone et al. (2001) & 10 & $0 /<10$ & 0 \\
BBMI & Boutilier et al. (2002) & 55 & $0 /<1.8$ & 0 \\
$\quad$ PLT4 & & & & \\
RKD1 & Köszegi et al. (2011) & 17 & $5 / 29$ & 5 \\
RKD2 & Köszegi et al. (2011) & 12 & $0 /<8.3$ & 0 \\
RKD4 & Waki et al. (2011) & 54 & $1 / 1.9$ & 0 \\
WUS & Zuo et al. (2002) & 30 & $1 / 3.3$ & 1 \\
WOX2 & Haecker et al. (2004) & 22 & $0 /<4.5$ & 0 \\
WOX5 & Sarker et al. (2007) & 71 & $0 /<1.4$ & 0 \\
WOX8 & Haecker et al. (2004) & 33 & $0 /<3.0$ & 0 \\
SERK1 & Hecht et al. (2001) & 23 & $0 /<4.3$ & 0 \\
SERK4 & Hecht et al. (2001) & 14 & $0 /<7.1$ & 0
\end{tabular}

All genes (see cited references) were transformed as UAS fusions into the M0171 line and the number of twin seedlings ( $n / \%)$ among T1 seedlings (number of lines) was scored, as well as the occurrence of twins in the T2 generation (heritable twins, number of lines) viable fertile plants (Fig. S1). The RKD1 and WUS-induced twinning was heritable but phenotypic penetrance was highly variable among RKD1 lines (Table S1). The failure to observe twin seedlings with any of the other embryo-promoting genes might reflect an inability to induce twins, very low efficiency or loss of strong phenotypes due to viability issues. Given that, for example, M0171 >>BBM-expressing plants showed morphological distortions at later developmental stages (Fig. S1), the constructs used probably did lead to ectopic gene expression. To directly test whether the ability to induce suspensor-derived twins among the genes tested is due to differences in gene expression levels, we analyzed transgene-derived gene expression in multiple independent lines expressing RKD1, RKD2, RKD4 and BBM from the M0171 driver in seedlings, in which the M0171 driver is also expressed (Radoeva et al., 2016). We found that the transgene expression level was comparable among transgenes (Fig. S2), which suggests that protein properties, rather than expression level, define the ability to induce twin embryos. We therefore conclude that there is a large difference in the ability to induce twin embryos among the potential regulators screened. Thus, the fate switch in suspensor cells from extra-embryonic to embryonic identity is a specific response that is triggered by a defined set of regulators.

\section{Diverse cell division patterns can mediate suspensor- derived embryogenesis}

The screen for embryo inducers was carried out at the seedling stage, yet the origin of the secondary embryo is expected to be in the suspensor. We therefore first tested whether the RKD1-induced twinning is accompanied by altered divisions in the suspensor. Indeed, although wild-type suspensors only showed anticlinal divisions (Fig. 1A), suspensors in M0171 > RKD1 plants showed early periclinal divisions (Fig. 1C). Given that, in addition to M0171 $\gg$ RKD1, other genotypes induced suspensor-derived embryos, we next investigated whether the cellular basis for embryo initiation is shared among these genotypes. We therefore compared early embryogenesis in M0171 $>$ RKD1, M0171 $>B D L$ and twin1 (Fig. 1H) genotypes. M0171 >>RKD4 and M0171 > WUS lines were omitted from this analysis because only single twinforming lines were identified for each genotype.

In wild-type embryos, all suspensor cells are derived from the basal zygote daughter cell through a series of anticlinal divisions (Fig. 1A). Only the uppermost hypophysis cell contributes to the root meristem and becomes part of the seedling (Fig. 1B). In all three transgenic (M0171 $>>$ RKD1; M0171 $>>b d l$ ) and mutant (twin1) genotypes analyzed, the quiescence of the suspensor was disrupted, as expressed by excessive divisions. In M0171 $>b d l$ embryos, excessive divisions were found to occur in anticlinal ('normal'), as well as periclinal and oblique planes. Although additional anticlinal divisions created longer suspensors, extra periclinal divisions led to the formation of clusters of small cells (Fig. 1E). As described previously (Rademacher et al., 2012), the first periclinal suspensor cell divisions usually occurred at the early globular stage (Fig. 1E). However, division defects were also observed in the pro-embryo (Radoeva et al., 2019). No twin seedlings were observed under standard growth conditions in M0171 >>bdl lines (Fig. 1F).

In contrast to the seemingly pleiotropic effect of bdl misexpression, M0171 >>RKD1 embryos followed a more regular division pattern. Excess divisions in suspensor cells were primarily periclinal, generating ordered multilayered suspensors, followed by the appearance of embryo-like cell clusters later during development (Fig. 1C). Although the timing of periclinal suspensor divisions 

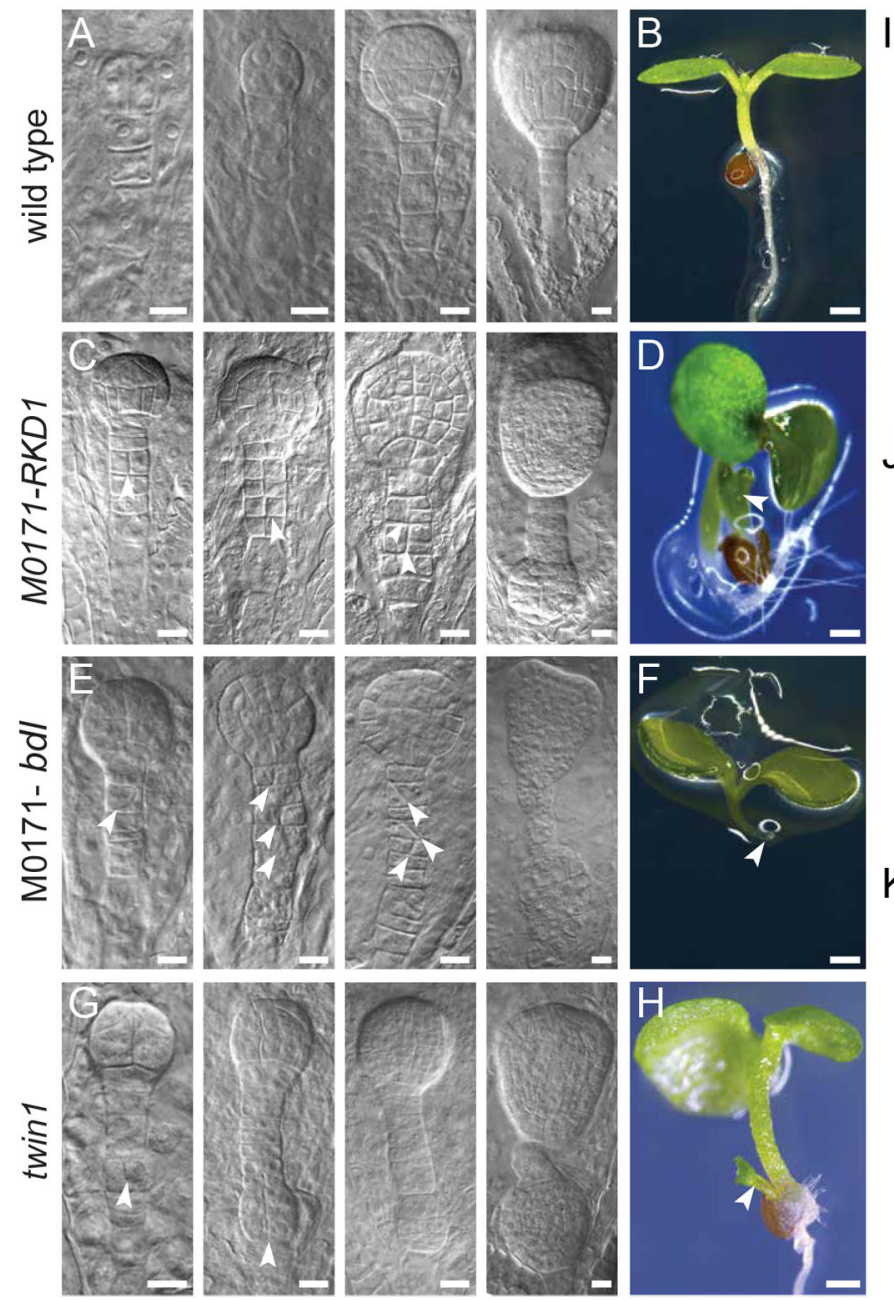

matched that observed in M0171 $>>b d l$ embryos, no conspicuous defects in the M0171 $>$ RKD1 pro-embryo were detected, and resulting seedlings had a normal appearance (Fig. 1D).

The recessive twin 1 mutant showed excessive divisions in the suspensor, and these included both anticlinal (longer suspensors) and periclinal divisions (Fig. 1G). The twinl mutant pro-embryo also showed division defects (Fig. 1G). Embryo-like structures developed in twin 1 suspensors later during development (Fig. 1G); their orientation could be the same as the original embryo, or the opposite (Fig. S3), and multiple embryos could initiate from the suspensor in a seemingly independent manner (Fig. S3).

We next examined whether the ontogenies of cell proliferation in suspensors of these three genotypes were similar. Therefore, we analyzed which suspensor cell showed the first periclinal division, as a clear sign for extra divisions. This analysis showed that the first defects occurred more frequently in the top half of the suspensor in M0171>>RKD1 and M0171 >>bdl lines (Fig. 1I,J), whereas there was no clear preferential origin of the defect in twin 1 embryos (Fig. 1K). The hypophysis was excluded from this analysis because $b d l$ misexpression specifically interferes with auxin-dependent root formation in this cell (Weijers et al., 2006).

Based on this phenotypic characterization, all three genotypes that induced suspensor-derived embryos appear to differ with respect to the position of origin in the suspensor, orientation of excessive cell divisions, development of the original pro-embryo

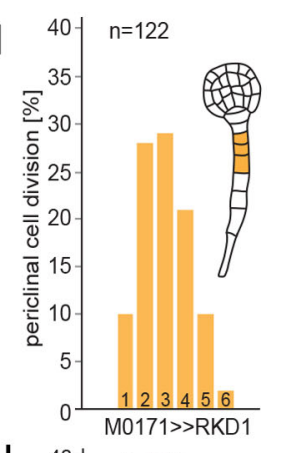

Fig. 1. Suspensor-derived twin embryo and seedling development. Wild-type $(A, B)$,

M0171 >>RKD1 (C,D), M0171 >>bdl (E,F) and twin1 $(G, H)$ embryo $(A, C, E, G)$ and seedling $(B, D, F, H)$

development. Imaged embryos were prepared from cleared ovules and seedling images were obtained using a light microscope. Successive embryo stages are shown in $A, C, E, G$, with embryos increasing in age from left to right. Periclinal suspensor divisions are marked with white arrowheads in $(\mathrm{C}, \mathrm{E}, \mathrm{G})$.

Arrowhead in $\mathrm{F}$ points to mutant root phenotype and to secondary twin embryos in $\mathrm{D}$ and $\mathrm{H}$. (I-K) Bar diagrams of the distribution of cells in which the first periclinal divisions are observed in M0171 >>RKD1, M0171 >>bdl and twin1 suspensors. Bar marked $\mathrm{H}$ represents the hypophyseal cell. No periclinal divisions were seen in a comparable number of wildtype embryos. The locations of preferential periclinal divisions are colored in each embryo cartoon. For wild-type, M0171 >>RKD1 and twin1, plants were selfed, whereas for M0171 >>bdl, parents were crossed. A T2 generation plant was used for M0171 > RKD1. Scale bars: $10 \mu \mathrm{m}$ in A,C,E,G; 1 $\mathrm{mm}$ in $\mathrm{B}, \mathrm{D}, \mathrm{F}, \mathrm{H}$. and the viability of embryo-like structures. It therefore appears that multiple paths can lead to suspensor-derived embryogenesis.

When analyzing embryo development in twin-producing lines, we noticed a higher frequency of altered suspensor divisions compared with the frequency of post-embryonic twins. We therefore systematically compared phenotypic penetrance at different stages. Although in $35 \%$ of M0171 $>$ RKD1 embryos $(n=366)$, periclinal suspensor divisions could be observed, only $9 \%$ of late-stage embryos showed a clear second suspensor-derived twin $(n=1590)$. Thus, fewer than one third of the embryos that showed periclinal divisions indeed developed twin embryos. This number is close to that observed in the twin 1 mutant in which $25 \%$ of the embryos $(n=234)$ showed periclinal suspensor divisions leading to only $13 \%$ of viable twin seedlings $(n=1172)$. The reduced phenotypic penetrance could mean that not all embryo-like structures have embryo identity. However, given the delay between suspensorderived and primary embryo development, it is also possible that spatial constraints or a failure to execute maturation or desiccation programs cause this difference.

\section{Loss of suspensor identity during suspensor-derived embryogenesis}

Suspensor-derived embryogenesis is associated with the activation of cell division in suspensor cells, a property shared by all three genotypes tested here. However, it is unclear whether the activation of cell division in the suspensor is intimately linked to the 

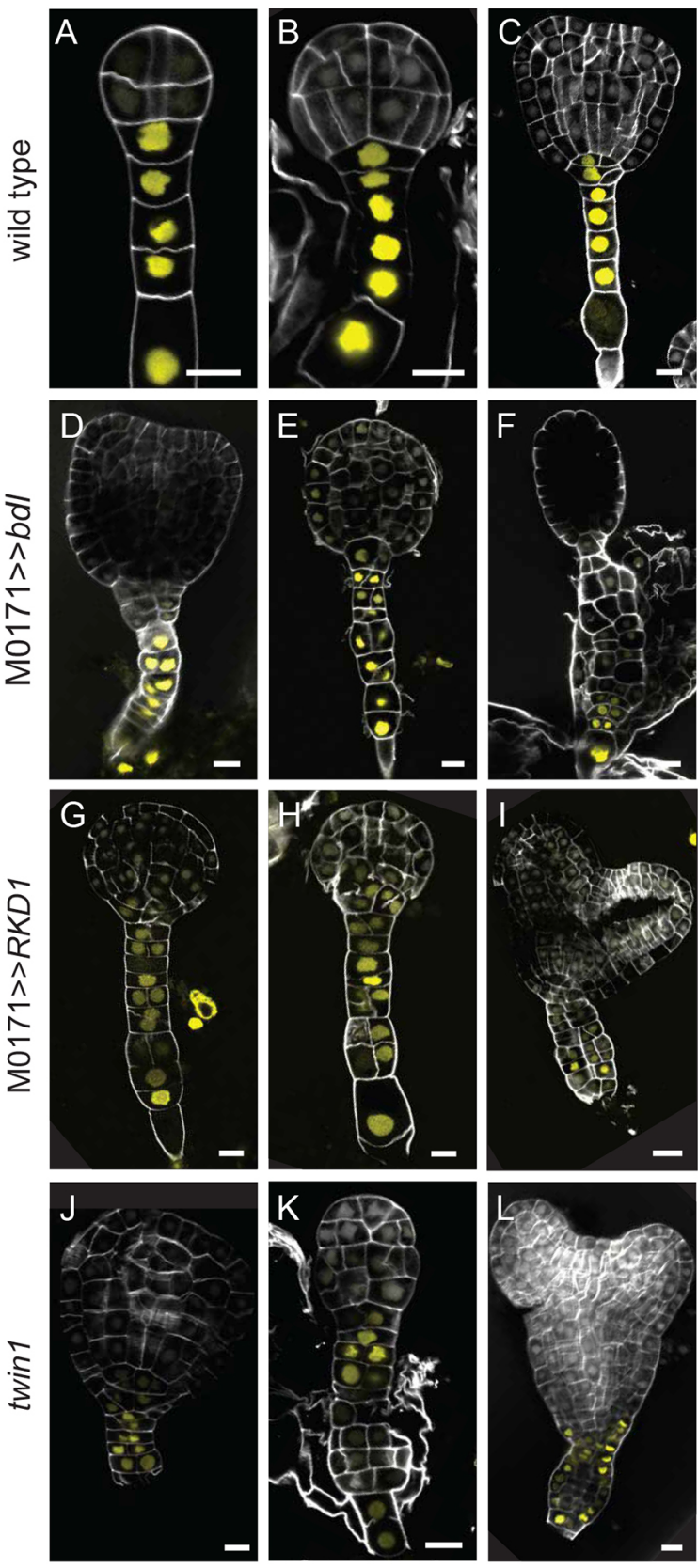

Fig. 2. Loss of suspensor marker expression after periclinal suspensor cell divisions. Expression of the pATPase::Venus suspensor marker (yellow) in wild-type (A-C), M0171 > >bdl (D-F), M0171>>RKD1 (G-I) and twin1 embryos (J-L). All embryos were released from developing seeds and imaged by confocal microscopy. For wild-type, M0171 >RKD1 and twin1, plants were selfed, whereas for M0171 > >bdl, parents were crossed. A T2 generation plant was used for M0171 > RKD1. Scale bars: $10 \mu \mathrm{m}$.

reprogramming of identities. Alternatively, embryo identity might be activated at any moment after a number of cells have been generated. To address this issue, we introduced markers for suspensor or embryo identity into each genotype and analyzed their expression during suspensor-derived embryogenesis.

We first generated a set of markers based on data from previous publications or on transcriptome data, and evaluated their usefulness as markers of either cell type in wild type (Table S2; Fig. S4). Three markers, pSUC3, pATPase and pWRKY2, faithfully marked suspensor cells and were introduced in all backgrounds. The expression of pATPase::Venus was strong in suspensor cells from at least the four-cell stage onwards (Fig. 2A) and was retained during the globular and late heart stage (Fig. 2B,C). In M0171 $>>b d l$ embryos, expression in suspensor cells was often lost when cells divided periclinally (Fig. 2D-F). However, not all cells that followed from periclinal division immediately lost pATPase::Venus expression. This result suggests that, although divisions are accompanied by a loss of this suspensor marker, downregulation is not likely immediately after division, or at least not before division. In M0171 > RKD1 embryos, pATPase::Venus expression was reduced throughout the suspensor and very few cells expressed the marker at the level found in wild-type suspensors (Fig. 2G). Some residual expression of this marker was retained in suspensor cells, even when these cells divided periclinally (Fig. 2H,I). Likewise, in twin I suspensors, the pATPase marker was also mostly lost when cells formed embryo-like structures (Fig. 2J-L). Analysis of pWRKY2 and pSUC3 markers in M0171 $>$ bdl and M0171 $>$ RKD1 embryos showed comparable results (Fig. S5). Hence, the activation of cell divisions in all three genotypes are indeed associated with the loss of suspensor markers. However, there is no immediate shutdown of marker expression upon the first periclinal division. Given that the suspensor cell cycle lasts $\sim 15 \mathrm{~h}$ (Gooh et al., 2015) and the half-life of the Venus variant used here is estimated to be $\sim 24 \mathrm{~h}$ (Snapp, 2009), it is highly possible that Venus signal is retained in divided cells, even if there is no more transcription after division. To address this issue, we quantified Venus signals in periclinally divided suspensor cells and found these to be approximately half of those observed in non-dividing and anticlinally divided cells (Fig. S6). This suggests that expression of suspensor-specific promoters is switched off during or after periclinal division.

\section{Division probably precedes loss of suspensor identity}

Given that periclinal division is associated with the loss of suspensor marker gene expression, and with the initiation of embryo-like structures, an important issue is whether the divisions are a consequence or a cause of reprogramming towards embryogenesis. In the former scenario, one would expect the loss of suspensor markers before cells first divide periclinally. As this would be difficult to infer from observing multiple embryos due to the variation of fluorescence levels within and between embryos, we used a liveimaging approach to establish the timing of division and expression of the pATPase- $3 x$ Venus marker in twin 1 mutant embryos. In wildtype embryos, occasional anticlinal divisions were observed during the observation time of $64 \mathrm{~h}$ (Fig. 3A), consistent with previous analysis of divisions in wild-type embryos (Gooh et al., 2015). Levels of pATPase-3xVenus marker fluorescence did not change noticeably before, during or after these anticlinal divisions (Fig. 3A). We observed several periclinal divisions in twinl mutant embryos (Fig. 3B,C). However, in these cells, we did not detect a change in pATPase-3xVenus expression before the periclinal division. Rather, expression decreased in daughter cells after the division. In some cases, expression of the marker was re-activated in one of the daughter cells (Fig. 3C). In conclusion, the loss of suspensor marker expression occurs after, not before or during, the periclinal division, which suggests that divisions are not the consequence of reprogramming. Rather, these divisions provide the cells in which reprogramming can occur.

\section{Activation of embryo identity in suspensor-derived embryos}

To determine when newly divided cells in the suspensor switch on an embryo program, we analyzed the expression of the pDRN:: Venus marker in the three genotypes. pDRN::Venus was selected 

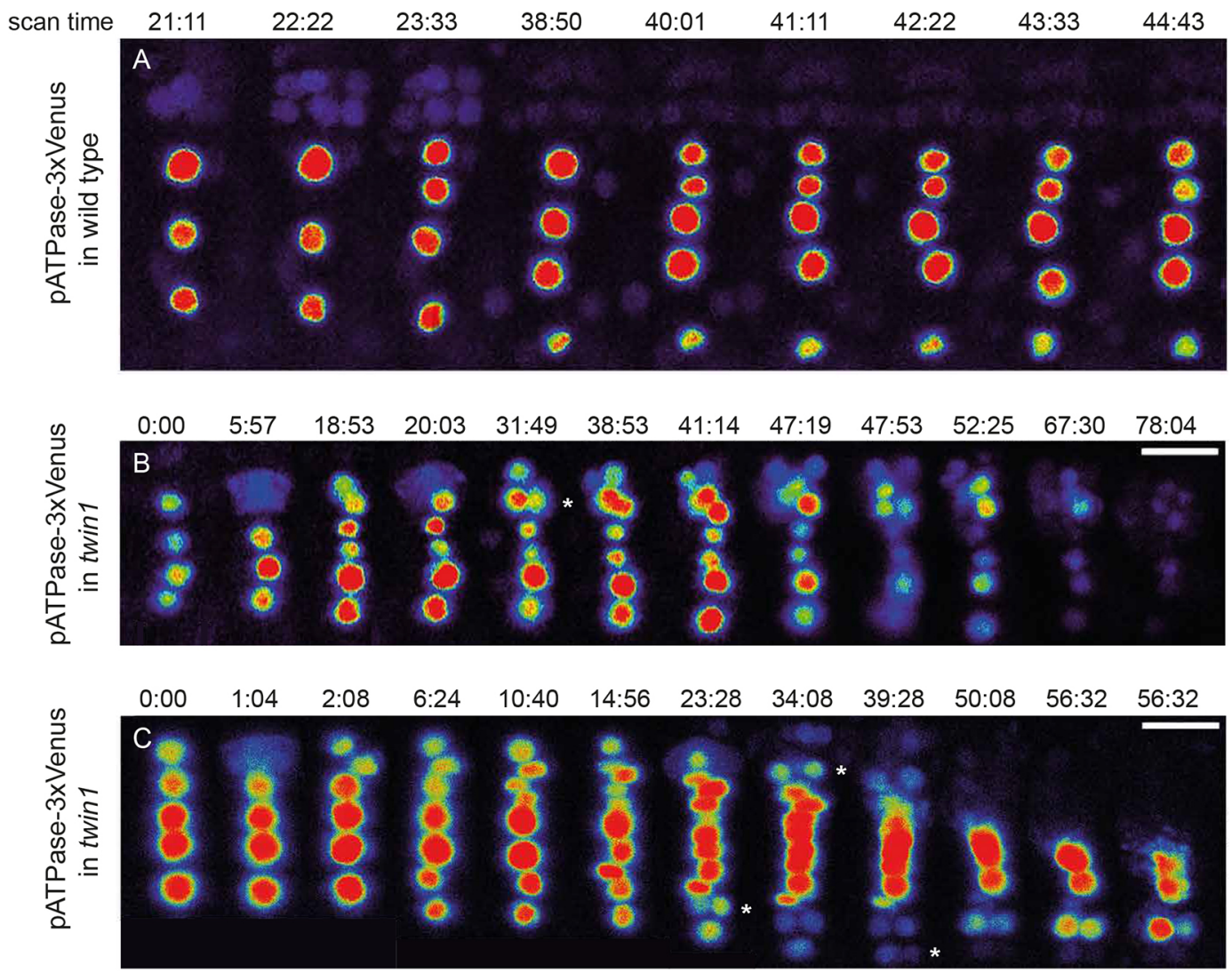

Fig. 3. Live imaging of suspensor marker expression in twin1 embryos. Time-lapse recordings of pATPase::Venus expression in wild-type embryos (A), and in two representatives of twin1 embryos $(B, C)$. No loss of pATPase::Venus signal intensity was observed in wild-type embryos for up to $45-50$ h of recording time. Scale bars: $10 \mu \mathrm{m}$. Asterisks indicate suspensor cells undergoing periclinal division during the time of recording.

from a larger collection (Table S2) based on its specificity and early expression in the wild-type pro-embryo at the four-cell stage (Fig. 4A). Following its activation in the apical cell(s), DRN expression persisted in the apical half of the early globular embryo (Fig. 4B) and became restricted to the shoot apical meristem (Fig. 4C). Despite clear expression in the pro-embryo, we could not detect activation of the DRN marker in dividing cells (Fig. 4D) and proliferating cell clusters (Fig. 4E,F) of M0171 $>>b d l$ suspensors. It should be noted though, that DRN is a direct target of the auxin response factor MP (Cole et al., 2009), the expression of which is activated in proliferating suspensor cells (Rademacher et al., 2012). It is therefore likely that $b d l$ expression in the suspensor will inhibit DRN expression irrespective of whether cells acquire embryo identity.

In contrast, periclinal divisions in suspensors of M0171 $>$ RKD1 embryos were accompanied by the activation of DRN expression (Fig. 4G-I). In most embryos, DRN expression was not seen until a small cluster of proliferating cells had been established in the suspensor (Fig. 4I). This same observation was also noted in twin 1 embryos (Fig. 4J-L). To address whether the cells observed after the loss of suspensor identity and before the acquisition of embryo identity followed a pathway mimicking egg cell identity, the reproductive expression cassette FGR7.0 (expressed in egg cell, synergids and central cell; Völz et al., 2013) was introduced in the twin1 mutant. No expression of any of the markers could be detected during periclinal divisions and the formation of twin embryos (Fig. S7).

The analysis of suspensor and embryo markers in three genotypes reveals that the process of reprogramming suspensor cells towards embryo identity is marked by periclinal cell divisions, loss of suspensor markers and gain of an embryo marker. It appears that in most cases, cell divisions and loss of suspensor identity occurs well before an embryo marker is activated. Of course, this could be caused by difficulties in detecting early DRN expression due to low phenotype penetrance and low expression levels. However, these observations are also consistent with a scenario in which reprogramming involves three distinct processes: loss of suspensor identity; cell proliferation; and gain of embryo identity.

\section{Is there a direct conversion of the suspensor into embryo identity?}

The analysis of the DRN marker in M0171 $>>$ RKD1 and twinl embryos shows that embryo identity is activated in newly formed cell clusters, but it is difficult to define the timing of activation relative to divisions. This is mainly because of the limited phenotypic penetrance, which complicates the detection of the earliest events. By propagating primary and secondary embryos from these two genotypes, we recovered lines that show a strongly increased phenotypic penetrance that allowed us to address the issue of whether there is a direct conversion of the suspensor into embryo identity.

As the suspensor-derived (secondary) embryo is initiated when the original (primary) pro-embryo is at the globular or heart stage (Fig. 1D,H), it is delayed and therefore smaller than the primary embryo at maturity. This causes a size difference between the larger primary and the smaller secondary seedling in twinl and M0171 $>$ RKD1 lines (Fig. 5A). We separately propagated primary and secondary seedlings from these genotypes and tested their progeny for the penetrance of twin phenotypes. Strikingly, the progeny from secondary seedlings showed much higher phenotype penetrance $(32 \% ; n=1311)$ compared with the primary seedling- 

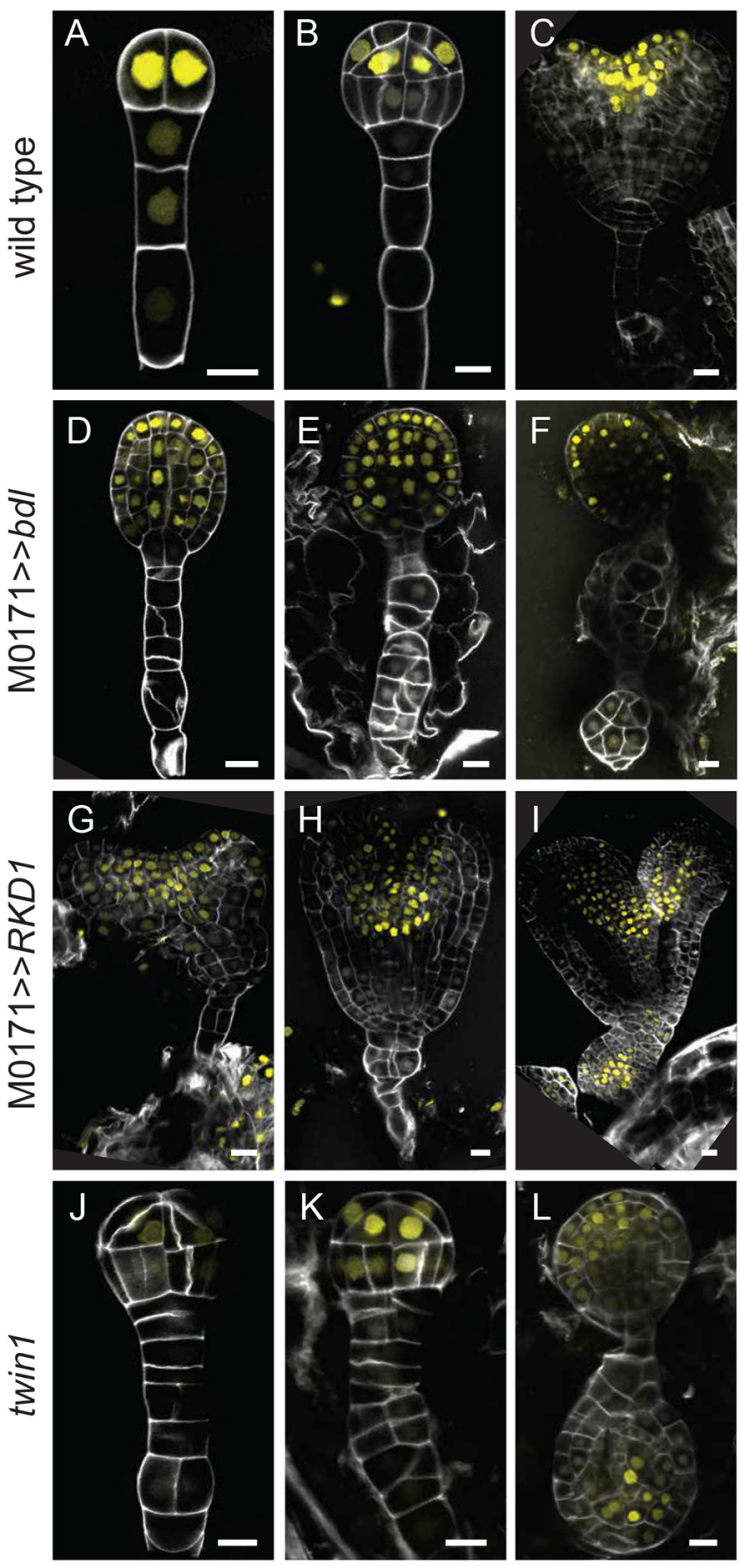

Fig. 4. Activation of embryo marker expression in suspensor-derived embryos. Expression of the pDRN::Venus pro-embryo marker (yellow) in wildtype (A-C), M0171 >>bdl (D-F), M0171>>RKD1 (G-I) and twin1 embryos $(\mathrm{J}-\mathrm{L})$. All embryos were released from developing seeds and imaged by confocal microscopy. For wild-type, M0171 > RKD1 and twin1 embryos, plants were selfed, whereas for M0171 > >bdl, parents were crossed. A T2 generation plant was used for M0171 > RKD1. Scale bars: $10 \mu \mathrm{m}$.

derived progeny in M0171 > RKD1 (Fig. 5A; 5\%; $n=1307$ ). In the secondary seedling-derived lines, triplet suspensor-derived embryos were occasionally seen and, in rare instances, gave rise to triplet seedlings (Fig. S3). In contrast, this difference was not observed in the twinl mutant [Fig. 5A; 16\% twins in primary $(n=2992) ; 15 \%$ twins in secondary $(n=3146)]$, suggesting the presence of an epigenetic component that acts on the regulation of the M0171 GAL4 driver. Indeed, the M0171>>RKD1 transgene was more strongly expressed in progeny seedlings of twin embryoderived plants than in primary embryo-derived plants (Fig. S2). We leveraged the increased phenotypic penetrance in secondary seedling-derived M0171 $>>$ RKD1 embryos to help identify the earliest stages of activation of the DRN marker. Indeed, we more readily identified periclinal suspensor cell divisions and substantially earlier expression of the DRN::Venus marker. This could be observed as early as after the first periclinal division in both daughter cells (Fig. 5B-D). We re-examined the twin 1 mutant in light of this observation, and this revealed that early DRN::Venus expression also occurs in this mutant (Fig. 5E). Thus, in addition to the 'late' DRN expression in cell clusters, there also appears to be a more direct conversion into embryo identity.

\section{DISCUSSION}

The occurrence of twin seedlings is a rare property in Arabidopsis and has only previously been found in the recessive twin 1 and twin 2 mutants (Vernon and Meinke, 1994), and upon the inhibition of auxin response (Rademacher et al., 2012). Here, we explored a candidate gene approach employing suspensor-specific expression of genes known to promote somatic embryogenesis. This revealed that three genes, RKD1, RKD4 and WUS, were able to induce twin seedlings. Of these, suspensor-specific expression of WUS and the egg-cell expressed gene RKD1 resulted in a heritable twin embryo and seedling phenotype.

One of the surprising findings is that transcription factors known to maintain embryo identity, such as BBM (Boutilier et al., 2002), LEC (Braybrook and Harada, 2008) and members of the WOX family (Haecker et al., 2004), did not readily induce twins in our assay. Given that expression levels of twin-inducing and noninducing transgenes were similar, a plausible interpretation is that the activity of embryo-inducing genes is strongly dependent on cellular context. Context-dependent action has been described for genes belonging to the BBM-AGL15-LEC pathway, which appear to be more active in immature zygotic embryos than in mature seedlings (Horstman et al., 2017). Apparently, context dependence also extends in the opposite direction to much earlier stages of embryo development as analyzed here.

The WUS gene is a homeobox-containing transcription factor that maintains the undifferentiated state of stem cells in the shoot apical meristem (Laux et al., 1996; Mayer et al., 1998). An activation tagging screen revealed WUS to be an effective inducer of somatic embryos from seedling roots (Zuo et al., 2002). It is therefore remarkable that suspensor-enhanced expression of a gene promoting the undifferentiated state results in countering the normally imposed block of embryogenic potential of the suspensor cells. Remarkably, in our screen, WUS is the only gene reported to promote embryogenesis out of context in root cells and also in suspensor cells. In a genomewide analysis of genes expressed in Arabidopsis somatic embryos, compared to leaf tissue and undifferentiated callus cells, WUS was found to be upregulated in somatic embryos (Wickramasuriya and Dunwell, 2015). Therefore, it appears that the cellular states underlying meristem pluripotency and embryogenesis share a common trigger.

RKD1 is a member of a small Arabidopsis gene family of RWPRK domain-containing proteins with transcription factor activity that were originally found as genes preferentially expressed in wheat egg cells (Köszegi et al., 2011). Ectopic expression of RKD1 resulted in callus formation with egg cell characteristics. Extensive analysis of multiple mutant combinations did not provide a clear role for RKD1 in female gametogenesis (Tedeschi et al., 2017) and no evidence was provided for RKD1 functions beyond potentially maintaining egg cell identity. Loss-of-function alleles of another member of this family, RKD4, impair zygote cell elongation and subsequent early divisions. Ectopic expression of RKD4 induces callus from which somatic embryos can form after depleting RKD4 (Waki et al., 2011). These results suggest a more general role of 

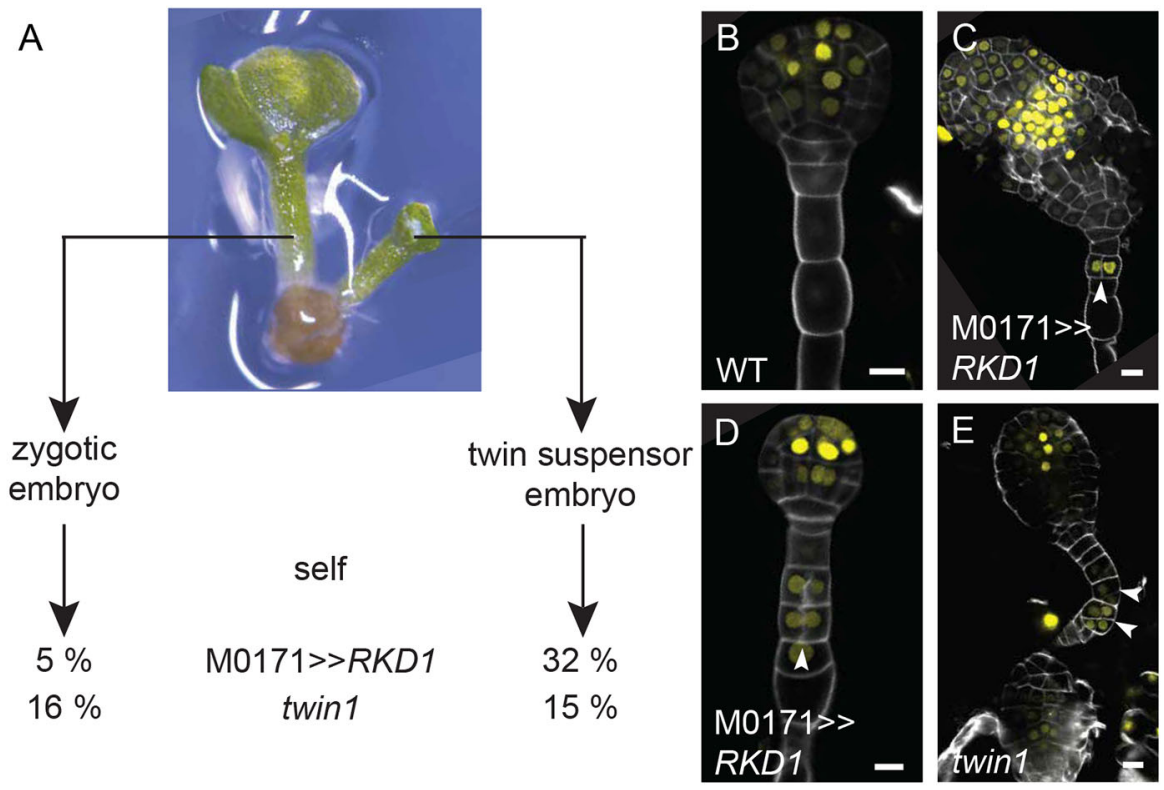

Fig. 5. Early embryo fate conversion in highpenetrance lines. (A) Three rounds of selfing using M0171 >>RKD1 and twin1, expressing the pDRN:: Venus marker produced lines that derived from the zygotic or from the suspensor-derived twin embryo. Between seven and 16 lines (over 1300 embryos in total) per transgene were analyzed for the indicated penetrance of the twin embryo phenotype.

(B-E) pDRN::Venus expression (yellow) in wild-type (WT) (B) and twin suspensor embryo-derived lines of M0171 >>RKD1 (C,D) and twin1 (E). All embryos were released from developing seeds and imaged using a confocal microscope. White arrowheads indicate single suspensor cells that express the proembryo marker pDRN::Venus. Scale bars: $10 \mu \mathrm{m}$.
RKD proteins in gametophyte identity and early embryogenesis (Koi et al., 2016). We found that transient RKD1 expression in suspensor cells leads to heritable twin-seedling formation. RKD4 had similar but more limited potential, as the single transgenic twin line did not show heritability of the phenotype. Given the proposed role of RKD1 in promoting egg cell identity, a plausible possibility would be that RKD1 expression caused suspensor cells to revert back to an egg cell state. This was not directly tested, but an egg cell marker was not activated during reprogramming in the $t w n 1$ mutant. It is therefore likely that RKD1 expression does not simply trigger egg cell identity in suspensor cells, and that its activity is also context dependent. It is intriguing that the only two genes we found to efficiently convert suspensor cells into embryogenic are those that appear to have a role in promoting an undifferentiated state in either the shoot meristem cells or in the egg cell.

A key event in induction of somatic embryos in plant tissue culture has long been considered to be dedifferentiation. As it is unlikely that cells entirely lose all aspects of their original identity, this event is perhaps better viewed as reprogramming. What follows is a mass of rapidly dividing cells (Fehér, 2019). Such cells exhibit a callus-like transcriptome (Che et al., 2006; Xu et al., 2012), and transcription factors such as WIND (Iwase et al., 2011) have been identified that promote subsequent steps in regeneration (Iwase et al., 2015). Few studies have addressed the issue of whether reprogramming followed by the acquisition of a new cell fate, such as 'embryogenic', first requires erasure of the previous somatic cell fate. Our results show that upon initiating periclinal cell division in suspensors, suspensor marker gene activity was generally reduced or totally absent. In the context of suspensor reprogramming, loss of existing cell identity is therefore indeed the first sign of cellular fate change. Propagating suspensor-derived M0171 >>RKD1 seedlings to later generations resulted in lines that showed increased penetrance of the twin-seedling phenotype, accompanied by strongly increased expression of the M0171 >>RKD1 transgene. Clearly, this suggests the existence of an epigenetic component involved in the fate conversion of suspensor cells into embryogenic cells. It should be noted that this effect was observed in M0171 > PKD1, but not twn1. The insertion site of the transgene in the M0171 could not be identified (Radoeva et al., 2016), and might reside in a genomic area with repeats or high GC content, perhaps sensitive to epigenetic phenomena. On the other hand, it is also possible that the process of reprogramming itself involves epigenetic components. Indeed, explants derived from somatic embryos often exhibit an increased frequency of embryogenic cell formation when compared with original explants (reviewed by Méndez-Hernández et al., 2019). Whether a link exists between this phenomenon and the recently discovered role of chromatin remodeling in embryogenic cell formation (reviewed by De-laPeña et al., 2015; Guo et al., 2020) remains to be determined. In twinl and in the high-penetrance RKD1 lines, DRN expression was activated almost immediately upon suspensor cell division, suggesting a direct conversion of suspensor cell into embryo fate. What this result shows is that reprogramming can, but need not, involve an intervening period of cell proliferation. Based on the similarities described above, we propose that suspensor-derived embryogenesis is closely related to the classical process of somatic embryogenesis.

\section{MATERIALS AND METHODS}

\section{Plant material and growth conditions}

The M0171 GAL4/GFP enhancer trap line was generated by Dr Jim Haseloff (University of Cambridge, UK) in the C24 ecotype (Haseloff, 1999) and was obtained from the Nottingham Arabidopsis Stock Center. All transcriptional Venus fusion lines and the pUAS-gene fusion lines were generated in the Columbia-0 (Col-0) ecotype.

Seeds were surface sterilized in a $25 \%$ bleach $/ 75 \%$ ethanol solution for $10 \mathrm{~min}$ and were then washed twice with $70 \%$ ethanol and once with $100 \%$ ethanol. Dried seeds were subsequently plated on half-strength Murashige and Skoog medium that contained the appropriate antibiotic $(50 \mathrm{mg} / \mathrm{l}$ kanamycin, $15 \mathrm{mg} / 1$ phosphinothricin or $0.1 \mathrm{mg} / \mathrm{l}$ methotrexate) for the selection of transgenic seeds. After $24 \mathrm{~h}$ incubation at $4{ }^{\circ} \mathrm{C}$, the plants were cultured in long-day ( $16 \mathrm{~h}$ light, $8 \mathrm{~h}$ dark) conditions at $22^{\circ} \mathrm{C}$.

\section{Cloning}

All cloning was carried out using a ligation-independent cloning system and the vectors used have been described previously (De Rybel et al., 2011; Wendrich et al., 2015). For generating the pUAS-fusion lines for M0171-drive misexpression, genomic fragments spanning the coding sequences were amplified from genomic DNA using Phusion Flash PCR Master Mix (Thermo Scientific) and cloned into vector pPLV132. To generate the transcriptional fusions, up to $3 \mathrm{~kb}$ fragments upstream of the ATG start codon were amplified from genomic DNA. After sequencing, the constructs 
were transformed into M0171 >>RKD1, UAS-bdl, twin1 and M0171 >>WUS lines by floral dipping (De Rybel et al., 2011). All primers used for cloning can be found in Table S3.

\section{Quantitative RT-PCR}

For measuring transgene expression levels in M0171 $\gg$ RKD1, M0171 >>RKD2, M0171>>RKD4 and M0171>>BBM lines, 12 6-dayold seedlings per line were pooled for RNA isolation. RNA was isolated using a combination of TRIzol reagent (Invitrogen) and an RNeasy kit (Qiagen). cDNA was then synthetized from $0.5 \mu \mathrm{g}$ total RNA using an iScript cDNA Synthesis Kit (Bio-Rad). Quantitative RT-PCR was performed using iQ SYBR Green Supermix (Bio-Rad) and CFX384 RealTime PCR Detection System (Bio-Rad). The qRT-PCR cycling conditions were $95^{\circ} \mathrm{C}$ for $10 \mathrm{~min} ; 45$ cycles of $95^{\circ} \mathrm{C}$ for $10 \mathrm{~s}, 58^{\circ} \mathrm{C}$ for $20 \mathrm{~s}$ and $72^{\circ} \mathrm{C}$ for $20 \mathrm{~s} ; 95^{\circ} \mathrm{C}$ for $10 \mathrm{~s}$; and $65^{\circ} \mathrm{C}$ for $5 \mathrm{~s}$, followed by dissociation curve analysis. Reactions were performed in triplicate, with two biological replicates. Transcript levels were normalized relative to the GAPC reference gene. All primers used for the qRT-PCR analysis are listed in Table S3.

\section{Microscopy and sample preparation}

Differential interference contrast (DIC) and confocal microscopy were carried out as described previously (Llavata-Peris et al., 2013) with minor modifications. For DIC imaging, ovules were isolated in chloral hydrate solution (chloral hydrate, water and glycerol, 8:3:1 w/v/v). After a short incubation, the embryos were viewed on a Leica DMR microscope equipped with DIC optics. For confocal imaging, ovules were isolated in $1 \times$ PBS containing $4 \%$ paraformaldehyde, $5 \%$ glycerol and $0.1 \%$ SCRI Renaissance Stain 2200 (R2200; Renaissance Chemicals) for the counterstaining of embryos. The embryos were taken out of the ovules by gently pressing the coverslip of slides containing ovules. R2200 and Venus fluorescence were visualized by excitation at $405 \mathrm{~nm}$ and $514 \mathrm{~nm}$, respectively, and detection between $430-470 \mathrm{~nm}$ and $524-540 \mathrm{~nm}$, respectively. Confocal imaging was performed on a Leica SP5 II system equipped with hybrid detectors

\section{Live embryo imaging}

For live imaging, the procedures described by Gooh et al. (2015) were employed with a number of modifications. M0171 >>bdl, M0171 >>RKD1 and twinl lines that showed a high penetrance of the twin-seedling phenotype and expressed pATPase::Venus markers were selected. Ovules $(\sim 50-80)$ were isolated and incubated on $300 \mu \mathrm{m}$ polydimethylsiloxane microcage arrays, which were modified by cutting a small channel in the device to allow better exchange with the surrounding Nitsch medium supplemented with 5\% w/v trehalose (Gooh et al., 2015). This resulted in ovules remaining alive and growing for up to $300 \mathrm{~h}$. Suspensor markers remained visible for at least $110 \mathrm{~h}$ of culture time using an hourly schedule of illumination.

Live embryo tracking was performed on a Leica SP8 with an inverted table controlled by the LAS AF and LAS X programs. A $20 \times$ water objective using $20 \%$ glycerol to prevent evaporation during long acquisition times was used. To visualize Venus fluorescence, excitation was carried out at $514 \mathrm{~nm}, 20 \%$ laser power and acquisition between $535 \mathrm{~nm}$ and $570 \mathrm{~nm}$. After manually pinpointing ovule positions, the program collected ten $z$ stack images at $10 \mu \mathrm{m}$ intervals (with the most intense image at the center). Images were taken every hour and there were $\sim 20$ ovules per microcage. Image data were optimized to obtain $z$-projections that were mounted in sequence. All projections were evaluated for the occurrence of anticlinal (wild type) and periclinal (mutant or transgene) suspensor cell divisions. The quality of fluorescent images was scored using an ad hoc scaling system between 0 and 4 .

\section{Acknowledgements}

The authors thank Rita Gross-Hardt for sharing the reproductive cell marker FGR7.0 David Meinke for the twin1 mutant; Thijs de Zeeuw for advice on live imaging; and Naomi Weertman for experimental support.

\section{Competing interests}

The authors declare no competing or financial interests.

\section{Author contributions}

Conceptualization: T.R., C.A., S.d.V., D.W.; Methodology: M.P.; Validation: T.R., C.A.; Formal analysis: T.R., C.A.; Investigation: T.R., C.A., M.P.; Writing - original draft: T.R., C.A., S.d.V., D.W.; Writing - review \& editing: T.R., C.A., S.d.V., D.W. Visualization: T.R., C.A.; Supervision: S.d.V., D.W.; Project administration: S.d.V., D.W.; Funding acquisition: D.W.

\section{Funding}

This work was supported by the Nederlandse Organisatie voor Wetenschappelijk Onderzoek (ALW-NSFC Grant 846.11.001 to D.W.).

\section{Supplementary information}

Supplementary information available online at

https://dev.biologists.org/lookup/doi/10.1242/dev.188912.supplemental

\section{Peer review history}

The peer review history is available online at

https://dev.biologists.org/lookup/doi/10.1242/dev.188912.reviewer-comments.pdf

\section{References}

Boutilier, K., Offringa, R., Sharma, V. K., Kieft, H., Ouellet, T., Zhang, L., Hattori, J., Liu, C.-M., Van Lammeren, A. A. M., Miki, B. L. A. et al. (2002). Ectopic expression of $\mathrm{BABY} B O O M$ triggers a conversion from vegetative to embryonic growth. Plant Cell 14, 1737-1749. doi:10.1105/tpc.001941

Braybrook, S. A. and Harada, J. J. (2008). LECs go crazy in embryo development. Trends Plant Sci. 13, 624-630. doi:10.1016/j.tplants.2008.09.008

Che, P., Lall, S., Nettleton, D. and Howell, S. H. (2006). Gene expression programs during shoot, root, and callus development in Arabidopsis tissue culture. Plant Physiol. 141, 620-637. doi:10.1104/pp.106.081240

Cole, M., Chandler, J., Weijers, D., Jacobs, B., Comelli, P. and Werr, W. (2009) DORNROSCHEN is a direct target of the auxin response factor MONOPTEROS in the Arabidopsis embryo. Development 136, 1643-1651. doi:10.1242/dev. 032177

De Rybel, B. D., van Den Berg, W., Lokerse, A., Liao, C.-Y., Van Mourik, H., Möller, B., Peris, C. L. and Weijers, D. (2011). A versatile set of ligationindependent cloning vectors for functional studies in plants. Plant Physiol. 156 1292-1299. doi:10.1104/pp.111.177337

De Vries, S. C. and Weijers, D. (2017). Plant embryogenesis. Curr. Biol. 27 , 870-873. doi:10.1016/j.cub.2017.05.026

De-la-Peña, C., Nic-Can, G. I., Galaz-Ávalos, R. M., Avilez-Montalvo, R. and Loyola-Vargas, V. M. (2015). The role of chromatin modifications in somatic embryogenesis in plants. Front. Plant Sci. 18, 635. doi:10.3389/fpls.2015.00635 Egertsdotter, U., Ahmad, I. and Clapham, D. (2019). Automation and scale up of somatic embryogenesis for commercial plant production, with emphasis on conifers. Front. Plant Sci. 10, 211. doi:10.3389/fpls.2019.00109

Fehér, A. (2019). Callus, dedifferentiation, totipotency, somatic embryogenesis: What these terms mean in the era of molecular plant biology? Front. Plant Sci. 10, 536 Gooh, K., Ueda, M., Aruga, K., Park, J., Arata, H., Higashiyama, T. and Kurihara, D. (2015). Live-Cell Imaging and Optical Manipulation of Arabidopsis Early Embryogenesis. Dev. Cell 34, 242-251. doi:10.1016/j.devcel.2015.06.008

Guo, H., Fan, Y., Guo, H., Wu, J., Yu, X., Wei, J., Lian, X., Zhang, L., Gou, Z., Fan, Y. et al. (2020). Somatic embryogenesis critical initiation stage-specific $\mathrm{mCHH}$ hypomethylation reveals epigenetic basis underlying embryogenic redifferentiation in cotton. Plant Biotechnol. J. doi:10.1111/pbi.13336

Haccius, B. (1955). Experimentally Induced Twinning in Plants. Nature. 176, 355-356. doi:10.1038/176355a0

Haecker, A., Groß-Hardt, R., Geiges, B., Sarkar, A., Breuninger, H., Herrmann, M. and Laux, T. (2004). Expression dynamics of WOX genes mark cell fate decisions during early embryonic patterning in Arabidopsis thaliana. Development. 131, 657-668. doi:10.1242/dev.00963

Haseloff, J. (1999). GFP variants for multispectral imaging of living cells. Methods Cell Biol. 58, 139-151. doi:10.1016/S0091-679X(08)61953-6

Hecht, V., Vielle-Calzada, J.-P., Hartog, M. V., Schmidt, E. D. L., Boutilier, K., Grossniklaus, U. and De Vries, S. C. (2001). The arabidopsis Somatic Embryogenesis Receptor Kinase 1 gene is expressed in developing ovules and embryos and enhances embryogenic competence in culture. Plant Physiol. 127 803-816. doi:10.1104/pp.010324

Horstman, A., Li, M., Heidmann, I., Weemen, M., Chen, B., Muino, J. M., Angenent, G. C. and Boutiliera, K. (2017). The BABY BOOM transcription facto activates the LEC1-ABI3-FUS3-LEC2 network to induce somatic embryogenesis. Plant Physiol. 175, 848-857. doi:10.1104/pp.17.00232

Ikeuchi, M., Sugimoto, K. and Iwase, A. (2013). Plant callus: Mechanisms of induction and repression. Plant Cell 25, 3159-3173. doi:10.1105/tpc.113.116053 Iwase, A., Mitsuda, N., Koyama, T., Hiratsu, K., Kojima, M., Arai, T., Inoue, Y., Seki, M., Sakakibara, H., Sugimoto, K. et al. (2011). The AP2/ERF transcription factor WIND1 controls cell dedifferentiation in arabidopsis. Curr. Biol. 21, 508-514 doi:10.1016/j.cub.2011.02.020 
Iwase, A., Mita, K., Nonaka, S., Ikeuchi, M., Koizuka, C., Ohnuma, M., Ezura, H., Imamura, J. and Sugimoto, K. (2015). WIND1-based acquisition of regeneration competency in Arabidopsis and rapeseed. J. Plant Res. 128, 389-397. doi:10. 1007/s10265-015-0714-y

Kawashima, T. and Goldberg, R. B. (2010). The suspensor: not just suspending the embryo. Trends Plant Sci. 15, 23-30. doi:10.1016/j.tplants.2009.11.002

Koi, S., Hisanaga, T., Sato, K., Ishizaki, K., Kohchi, T., Nakajima, K., Shimamura, M. and Yamato, K. T. (2016). An Evolutionarily Conserved Plant RKD Factor Controls Germ Cell Differentiation. Curr. Biol. 26, 1775-1781. doi:10. 1016/j.cub.2016.05.013

Köszegi, D., Johnston, A. J., Rutten, T., Czihal, A., Altschmied, L., Kumlehn, J., Wüst, S. E. J., Kirioukhova, O., Gheyselinck, J., Grossniklaus, U. et al. (2011). Members of the RKD transcription factor family induce an egg cell-like gene expression program. Plant J. 67, 280-291. doi:10.1111/j.1365-313X.2011.04592.x

Lakshmanan, K. K. and Ambegaokar, K. B. (1984). Polyembryony. In Embryology of Angiosperms, pp. 445-474

Laux, T., Mayer, K. F. X., Berger, J. and Jürgens, G. (1996). The WUSCHEL gene is required for shoot and floral meristem integrity in Arabidopsis. Development 122, 87-96

Liu, Y., Li, X., Zhao, J., Tang, X., Tian, S., Chen, J., Shi, C., Wang, W. and Zhang, L. (2015). Direct evidence that suspensor cells have embryogenic potential that is suppressed by the embryo proper during normal embryogenesis. Proc. Natl. Acad. Sci. USA 112, 12432-12437. doi:10.1073/pnas.1508651112

Llavata-Peris, C., Lokerse, A., Möller, B., De Rybel, B. and Weijers, D. (2013) Imaging of phenotypes, gene expression, and protein localization during embryonic root formation in arabidopsis. Methods Mol. Biol. 959, 137-148. doi:10.1007/978-1-62703-221-6_8

Lotan, T., Ohto, M., Yee, K. M., West, M. A., Lo, R., Kwong, R. W., Yamagishi, K. Fischer, R. L., Goldberg, R. B. and Harada, J. J. (1998). Arabidopsis LEAFY COTYLEDON1 is sufficient to induce embryo development in vegetative cells. Cell 93, 1195-1205. doi:10.1016/s0092-8674(00)81463-4

Mayer, K. F. X., Schoof, H., Haecker, A., Lenhard, M., Jürgens, G. and Laux, T. (1998). Role of WUSCHEL in regulating stem cell fate in the Arabidopsis shoot meristem. Cell 95, 805-815. doi:10.1016/S0092-8674(00)81703-1

Méndez-Hernández, H. A., Ledezma-Rodríguez, M., Avilez-Montalvo, R. N. Juárez-Gómez, Y. L., Skeete, A., Avilez-Montalvo, J., De-La-Peña, C. and Loyola-Vargas, V. M. (2019). Signaling overview of plant somatic embryogenesis. Front. Plant Sci. 10, 203. doi:10.3389/fpls.2019.00077

Palovaara, J., de Zeeuw, T. and Weijers, D. (2016). Tissue and Organ Initiation in the Plant Embryo: A First Time for Everything. Annu. Rev. Cell Dev. Biol. 32 , 47-75. doi:10.1146/annurev-cellbio-111315-124929

Rademacher, E. H., Lokerse, A. S., Schlereth, A., Llavata-Peris, C. I., Bayer, M., Kientz, M., FreireRios, A., Borst, J. W., Lukowitz, W., Jürgens, G. et al. (2012) Different Auxin Response Machineries Control Distinct Cell Fates in the Early Plant Embryo. Dev. Cell 22, 211-222. doi:10.1016/j.devcel.2011.10.026

Radoeva, T. and Weijers, D. (2014). A roadmap to embryo identity in plants. Trends Plant Sci. 19, 709-716. doi:10.1016/j.tplants.2014.06.009

Radoeva, T., Hove, C. A. T., Saiga, S. and Weijers, D. (2016). Molecular characterization of arabidopsis GAL4/UAS enhancer trap lines identifies nove cell-type-specific promoters. Plant Physiol. 171, 1169-1181. doi:10.1104/pp.16. 00213
Radoeva, T., Lokerse, A. S., Llavata-Peris, C. I., Wendrich, J. R., Xiang, D., Liao, C.-Y., Vlaar, L., Boekschoten, M., Hooiveld, G., Datla, R. et al. (2019). A robust auxin response network controls embryo and suspensor development through a basic helix loop helix transcriptional module. Plant Cel/ 31, 52-67. doi:10.1105/tpc. 18.00518

Sarkar, A. K., Luijten, M., Miyashima, S., Lenhard, M., Hashimoto, T., Nakajima K., Scheres, B., Heidstra, R. and Laux, T. (2007). Conserved factors regulate signalling in Arabidopsis thaliana shoot and root stem cell organizers. Nature $\mathbf{4 4 6}$ 811-814. doi:10.1038/nature05703

Schwartz, B. W., Yeung, E. C. and Meinke, D. W. (1994). Disruption of morphogenesis and transformation of the suspensor in abnormal suspensor mutants of Arabidopsis. Development 120, 3235-3245.

Snapp, E. L. (2009). Fluorescent proteins: a cell biologist's user guide. Trends Cell Biol. 19, 649-655. doi:10.1016/j.tcb.2009.08.002

Stone, S. L., Kwong, L. W., Yee, K. M., Pelletier, J., Lepiniec, L., Fischer, R. L., Goldberg, R. B. and Harada, H. J. et al. (2001). LEAFY COTYLEDON2 encodes a B3 domain transcription factor that induces embryo development. Proc. Natl. Acad. Sci. USA 98, 11806-11811. doi:10.1073/pnas.201413498

Tedeschi, F., Rizzo, P., Rutten, T., Altschmied, L. and Bäumlein, H. (2017) RWP-RK domain-containing transcription factors control cell differentiation during female gametophyte development in Arabidopsis. New Phytol. 213, 1909-1924. doi:10.1111/nph.14293

Vernon, D. M. and Meinke, D. W. (1994). Embryogenic Transformation of the Suspensor in twin, a Polyembryonic Mutant of Arabidopsis. Dev. Biol. 165 566-573. doi:10.1006/dbio.1994.1276

Völz, R., Heydlauff, J., Ripper, D., von Lyncker, L. and Groß-Hardt, R. (2013). Ethylene Signaling Is Required for Synergid Degeneration and the Establishment of a Pollen Tube Block. Dev. Cell 25, 310-316. doi:10.1016/j.devcel.2013.04.001

Waki, T., Hiki, T., Watanabe, R., Hashimoto, T. and Nakajima, K. (2011). The arabidopsis RWP-RK protein RKD4 triggers gene expression and pattern formation in early embryogenesis. Curr. Biol. 21, 1277-1281. doi:10.1016/j.cub. 2011.07.001

Weijers, D., van Hamburg, J.-P., van Rijn, E., Hooykaas, P. J. J. and Offringa, R. (2003). Diphtheria toxin-mediated interregional communication seed development. Plant Physiol. 133, 1882-1892. doi:10.1104/pp.103.030692

Weijers, D., Schlereth, A., Ehrismann, J. S., Schwank, G., Kientz, M. and Jürgens, G. (2006). Auxin triggers transient local signaling for cell specification in Arabidopsis embryogenesis. Dev. Cell 10, 265-270. doi:10.1016/j.devcel.2005 12.001

Wendrich, J. R., Möller, B. K., Uddin, B., Radoeva, T., Lokerse, A. S., De Rybel, B. and Weijers, D. (2015). A set of domain-specific markers in the Arabidopsis embryo. Plant Reprod. 28, 153-160. doi:10.1007/s00497-015-0266-2

Wickramasuriya, A. M. and Dunwell, J. M. (2015). Global scale transcriptome analysis of Arabidopsis embryogenesis in vitro. BMC Genomics 16, 1411. doi:10. 1186/s12864-015-1504-6

Xu, K., Liu, J., Fan, M., Xin, W., Hu, Y. and Xu, C. (2012). A genome-wide transcriptome profiling reveals the early molecular events during callus initiation in Arabidopsis multiple organs. Genomics. 100, 116-124. doi:10.1016/j.ygeno.2012. 05.013

Zuo, J., Niu, Q.-W., Frugis, G. and Chua, N.-H. (2002). The WUSCHEL gene promotes vegetative-to-embryonic transition in Arabidopsis. Plant J. 30, 349-359. doi:10.1046/j.1365-313X.2002.01289.x 